\title{
Incentive Systems in a Real Effort Experiment
}

Frans van Dijk, Joep Sonnemans and Frans van Winden

\begin{abstract}
In the reported experiment different payment schemes are examined on their incentive effects. Payment based on individual, team and relative performance are compared. Subjects conducted computerized tasks that required substantial effort. The results show that individual and team payment induced the same effort levels. In team production free-riding occurred, but it was compensated by many subjects providing more effort than in case of individual pay. Effort was higher, but more variable in tournaments, while in case of varying abilities workers with relatively low ability worked very hard and drove up effort of the others. Finally, attitudes towards work and other workers differed strongly between conditions.
\end{abstract}

November 1997

Address:

Faculty of Economics and Econometrics

University of Amsterdam

Roetersstr. 11, 1018 WB Amsterdam

The Netherlands

tel. $+31-205254126$

fax.+31-205255283

e-mail: CREED@fee.uva.nl

*Financial support by the Netherlands' Organization for Scientific Research (NWO) is gratefully acknowledged. We thank Otto Perdeck for his help and support in an early phase of this project and Peter van de Hoef for programming. We also thank Jordi Brandts, Gary Bornstein, Jacob Goeree, Charles Holt, Hessel Oosterbeek and participants of AWEE '97 and ESA September '97 for their comments. 


\section{Introduction}

The work effort supplied by employees is crucial to the performance of organizations. Accordingly, the incentive effects of different payment schemes on effort have received much attention in the theoretical literature. The efficiency of payment schemes such as hourly wages, piece-rate pay, relative pay (in particular, rank-order tournaments) and team remuneration has been subject of study (see e.g. Lazear, 1995, Kandel and Lazear, 1992). In contrast to this vast literature, few empirical field studies have been undertaken to compare the effects of different compensation methods. In a recent review Prendergast states that: "... there is surprisingly little clear-cut evidence that changing incentive provisions within firms affects worker behavior" (Prendergast, 1996, p.4). An important exception is a study by Lazear (1996) which examines the consequences of the replacement of hourly wages by piece rates in a specific factory. Lazear records an output increase of $36 \%$, more than half of which is caused by workers producing more due to incentive effects, the other part being caused by retaining and attracting more productive workers, while loosing less productive workers. With regard to rank-order tournaments some support for the theory is found (see Knoeber and Thurman, 1994), but an empirical comparison with other payment schedules is not available. Also, behavior of individuals in teams has hardly been examined in work environments. Prendergast (1996) cites some papers about legal and medical practices which seem to indicate that free-riding effects dominate peer pressure.

In addition, some experiments have been conducted. Bull et al. (1987) find, for example, that rankorder tournament theory explains average behavior in the laboratory rather well, but that a large variance of behavior across identical tournaments exists. In this and later experiments (Schotter and Weigelt, 1992, Nalbatian and Schotter, 1997) subjects are not required to work. Instead they were asked to choose an "effort level". The higher the effort chosen the higher the earnings in case of piece rates, or the higher the probability of winning in a rank-order tournament. Associated with effort are costs that increase with effort. These costs capture the negative utility workers supposedly derive from exerting effort. The same approach is followed by Fehr et al. (1993) who examine the relationship between wage level and effort, but also do not let their subjects really work. They find that the effort subjects are willing to provide increases with the wage level. In contrast, Erev et al. (1993) have conducted a field experiment in which subjects had to pick oranges in an orchard. Their study focuses on intergroup competition, and compares individual rewards, team rewards and a payment schedule based on the relative output of teams. Results show that in the team condition effort declines rapidly and falls substantially short of effort provided under individual rewards. Intergroup competition, 
brought about by rewarding relative team performance, appears to eliminate this loss of productivity. To our knowledge no other experiments are available that test the theoretical predictions of team reward models in a work setting. Of course, public good experiments in general are relevant. In these experiments, the key aspect is free-riding which is found to depend on a host of factors, such as pay-off structure, group size and the degree to which communication is allowed (Ledyard, 1995).

Except for the field experiment of Erev et al. (1993), these experiments are all highly abstract. There are indications that this affects outcomes. To illustrate the potential difference between allocating budgets and allocating real effort we refer to volunteer work. People seem often willing to provide considerable amounts of labor, while they would not be willing to contribute equivalent amounts of money. A major goal of this paper is to examine effort under different payment schemes in an experimental environment which resembles real work. In analyzing a worker's effort for an employer a distinction can be made between (a) the extent she exerts herself (e.g., work pace) when actually working on assigned tasks, and (b) the time she spends on these tasks and not on other activities such as reading the newspaper, surfing the net or talking to colleagues. The latter aspect seems to be particularly important ${ }^{1}$. The actual performance (output) of a worker is further affected by (c) ability and (d) chance. Stochastic events may be common for all workers on the same job or be worker specific. In our experiment subjects performed cognitively demanding tasks on the computer during a number of periods. In each period they could work on two tasks that could not be finished within the time constraints. For task A - work for the employer - the payment scheme was varied, while task B other activity in the employer's time - was always rewarded individually on a piece-rate basis. In principle, this set-up allows both of the aforementioned aspects (a) and (b) of effort to play a role. However, to facilitate the analysis we attempted and succeeded to eliminate factor (a). As a result, the focus can be on the allocation of effort.

The tasks consisted of solving two-variable optimization problems by trial and error. This type of task was chosen because it is absorbing and demanding. It requires full concentration. Also, the output is exactly measurable. Finally, these tasks correspond with (key elements of) actual jobs ${ }^{2}$. Due to the

\footnotetext{
${ }^{1}$ A recent report states that workers with access to the internet spend 5 to 10 hours a week to send personal email or search for information not specifically related to their jobs (see International Herald Tribune 23-9-97). Furthermore, it is not evident that an individual operates on different effort levels. It could even be the case that total effort is rather constant and what mostly matters is the allocation of effort. In that case aspect (a) does not play an important role.

${ }^{2}$ This type of task has been developed in ergonomics to capture key aspects of the jobs of process/system operators (Bridger and Long, 1984).
} 
nature of the tasks differences in ability may occur among subjects; moreover, an individual-specific chance element is involved (see $\mathrm{c}$ and $\mathrm{d}$ above). Three incentive systems are compared: individual piecerate pay, team remuneration and compensation based on rank-order tournaments. Team rewards and tournaments are examined in a two-person context.

The main results can be summarized in four conclusions: (1) individual piece rate and team payment induce the same effort levels (for the employer), (2) in team production free-riding occurs, but it is compensated by many subjects providing more effort than in case of individual pay, while no end-effect is observed, (3) effort is higher, but more variable in tournaments, and (4) in case of varying abilities in tournaments workers with relatively low ability work very hard and drive up effort of the others. In the concluding section we compare our results with the experiments mentioned above.

To facilitate notation, we will discuss the design of the experiment in section 2 before we turn to the hypotheses in section 3 . Section 4 gives the results, while section 5 concludes.

\section{Design}

\subsection{Description of tasks and payment schemes}

The work requested from subjects consisted of two-variable optimization tasks which we derived from the ergonomic literature (e.g., Bridger and Long, 1984). In a different economic application, the same sort of task was used by Pingle $(1995,1997)$. In each task subjects had to search by trial and error the two-dimensional space $\mathrm{S}=\{(\mathrm{H}, \mathrm{V}): \mathrm{H}, \mathrm{V} \in[-\mathrm{a}, \mathrm{a}]$, with a an integer $\}$ in order to find the highest possible value of a single-peaked function. The value reached on a task by a subject at the end of the time period allotted for that task is the subject's result on that task, denoted by $\mathrm{R}$, which is exactly measurable. Formally, $\mathrm{R}=\mathrm{h}(\mathrm{H}, \mathrm{V})$. Search started at $(\mathrm{H}, \mathrm{V})=(0,0)$, and $\mathrm{H}$ and $\mathrm{V}$ could be increased or lowered in discrete steps of 1 (further called moves). For h the following function was used:

$$
R=h(H, V)=\alpha\left\{b_{3}-\left[\left(a_{1} H-b_{1}\right)^{2}+\left(a_{2} V-b_{2}\right)^{2}+c\left(a_{1} H-b_{1}\right)\left(a_{2} V-b_{2}\right)\right]^{b_{4}}\right\}
$$

The function describes a solid of revolution. If $b_{4}$ equals .5 , this is a cone. In case $b_{4}$ is 1 , a paraboloid results. The maximum of this function, denoted by $R^{\max }$, is $\alpha b_{3}$ which is reached for $H=b_{1} / a_{1}$ and $V=$ 
$b_{2} / a_{2}$. Throughout, $b_{3}$ was kept constant, while $\alpha$ was used to scale the results. A set of tasks was generated by varying other parameter values. Parameters were constrained in such a way that in all tasks $\mathrm{R}=0$ for $(\mathrm{H}, \mathrm{V})=(0,0)$, and the shortest route to the maximum always consisted of 25 steps.

In each period of the experiment subjects could work on two tasks, task A and task B, during a known fixed time period. Their results on both tasks in a period determined their payoff in that period. Both tasks were of the same type and difficulty. In Figure 1 the computer screen that subjects saw when working is depicted (a translation of the instructions they received is provided in the Appendix). Each period lasted 50 seconds, while a lag of 1.5 seconds between two moves was built in to reduce the advantage of experienced players of computer games. When a new period started, subjects received a message on their screens asking them with which task they wanted to start. Once they had taken their decisions, the computer screen of Figure 1 appeared, and they could start working. They could switch tasks whenever they wanted. Also, within a task they could switch from $\mathrm{H}$ to $\mathrm{V}$ and vice versa at any moment ${ }^{3}$. For task A the payment scheme was varied. task B served to control opportunity costs, and

3 A demo of the program is available on the World Wide Web (http://www.fee.uva.nl/vak_groep/CREED/effort.htm). 
was always rewarded on an individual piece rate basis. The idea behind this set-up is as follows.
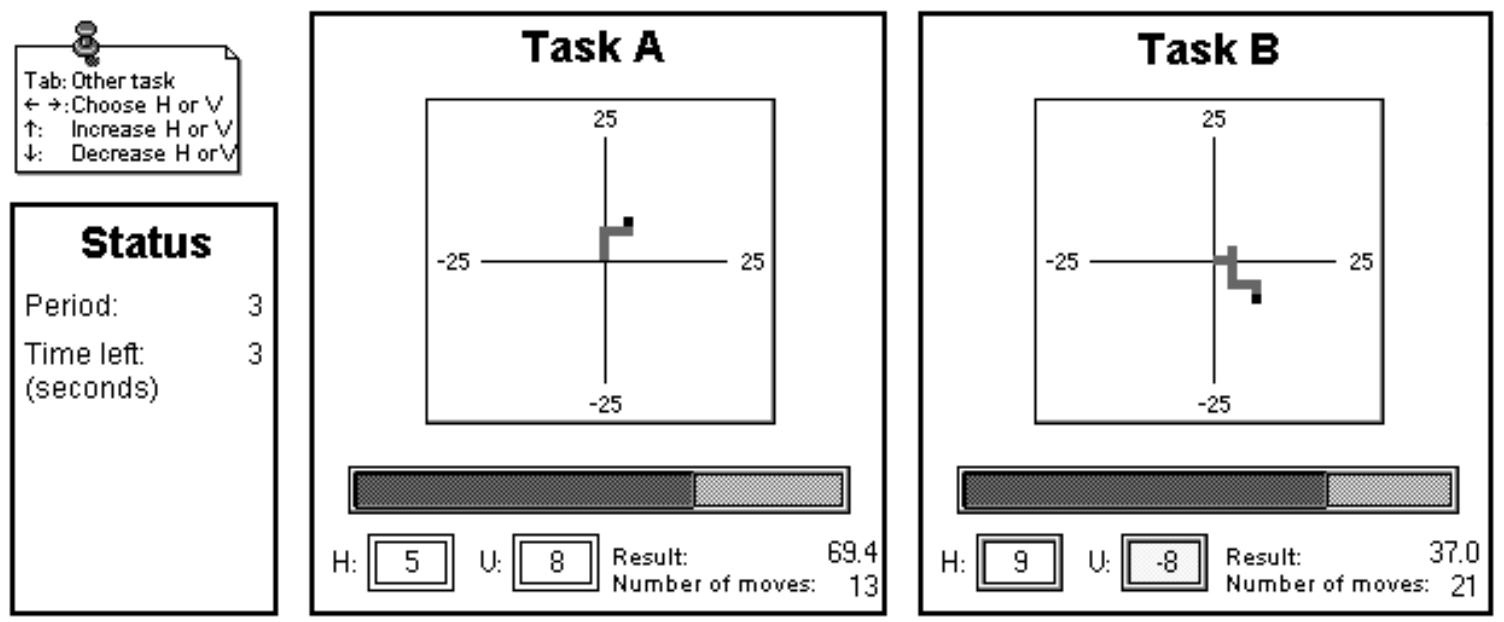

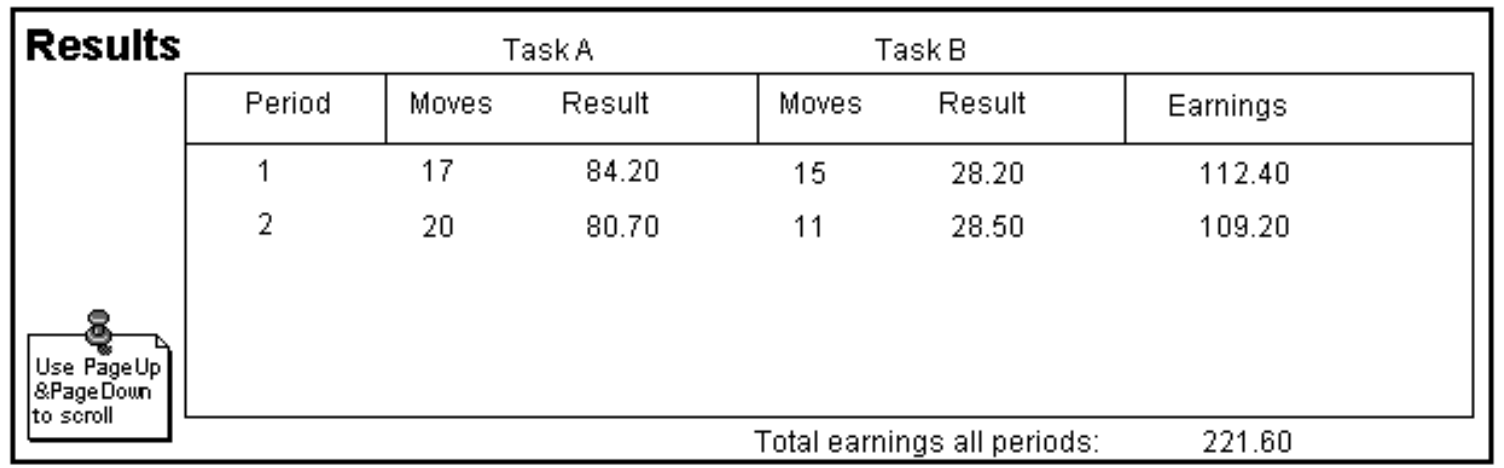

Figure 1: The computer screen (translated from Dutch).

Task A is work for the employer, while task B captures activities that can also be undertaken in the boss' time, but are only rewarding for the worker. In actual work situations, these activities take many forms. Some examples are reading newspapers and magazines, surfing the net, talking with colleagues, etc. Key is that these activities require time and effort, and provide utility to the worker.

The result a worker $i$ achieves is denoted by $\mathrm{R}_{\mathrm{Xi}}$ with $\mathrm{X}=\mathrm{A}, \mathrm{B}$ and $\mathrm{R}_{\mathrm{Xi}} \leq \mathrm{R}_{\mathrm{X}}{ }^{\mathrm{max}}$. The time constraints are set in such a way that subjects are generally unable to reach $\mathrm{R}_{\mathrm{x}}{ }^{\mathrm{max}}$, even when they work only on task $\mathrm{X}$. The number of moves on a task in the $\mathrm{V}$ - and H-directions together is denoted by $\mathrm{M}_{\mathrm{Xi}}, 0 \leq \mathrm{M}_{\mathrm{xi}} \leq$ $\mathrm{M}_{\mathrm{X}}{ }^{\mathrm{max}}$, where $\mathrm{M}_{\mathrm{X}}{ }^{\mathrm{max}}$ is the maximum number of moves technically possible given the time and technical constraints if one works only on X. In practice, subjects generally cannot reach this maximum. The total number of moves is denoted by $\mathrm{M}_{\mathrm{i}}$ and equals $\mathrm{M}_{\mathrm{Ai}}+\mathrm{M}_{\mathrm{Bi}}$. A relationship exists between result and moves for a task. Along the path starting at $\left(\mathrm{H}_{\mathrm{Xi}}, \mathrm{V}_{\mathrm{Xi}}\right)=(0,0)$ and leading to the largest increments of $\mathrm{R}$, 
$\mathrm{R}_{\mathrm{Xi}}$ is a function of $\mathrm{M}_{\mathrm{Xi}}$. Given the above specification of the function $\mathrm{h}, \partial \mathrm{R}_{\mathrm{Xi}} / \partial \mathrm{M}_{\mathrm{Xi}}>0$ and $\partial^{2} \mathrm{R}_{\mathrm{Xi}} / \partial \mathrm{M}_{\mathrm{Xi}^{2}}^{2}$ $<0^{4}$. Subjects do not know this optimal path, and therefore deviate from it. This implies that a subject's result on a task depends not only on the number of moves within a period on a task, but also on chance as some moves improve the result more than others which in many instances cannot be known in advance. Some moves may even decrease the result.

Earnings from a task are denoted by $\mathrm{P}_{\mathrm{Xi}}$ and total pay by $\mathrm{P}_{\mathrm{i}}=\mathrm{P}_{\mathrm{Ai}}+\mathrm{P}_{\mathrm{Bi}}$. As mentioned above, task $\mathrm{B}$ is always rewarded individually (piece rate with $\mathrm{P}_{\mathrm{Bi}}=\mathrm{R}_{\mathrm{Bi}}$ ), whereas the payment schemes for task $\mathrm{A}$ differ. Table 1 shows the payment schemes used for task A. With team-rewards earnings are based on the average result for the two group members. Note that this constitutes in a sense a worst case for team remuneration and production. The costs associated with the measurement of output are likely to be lower for teams than for individual workers. We do not take this into account. Also, we ignore production externalities. In the tournament, the payment for task $\mathrm{A}$ is dependent on the relative performance of the two group members. The subject who "wins" (has a higher result on task A) gets the price $\mathrm{W}$, while the other gets only $\mathrm{L}$ or 0 (if she does not work on A at all). If results are exactly the same and positive, both subjects get the average of $\mathrm{W}$ and $\mathrm{L}$.

Table 1. Payment schemes for task A.

\begin{tabular}{|l|l|l|}
\hline individual piece rate & two-person team remuneration & two-person rank-order tournament \\
\hline $\mathrm{P}_{\mathrm{Ai}}=\mathrm{R}_{\mathrm{Ai}}$ & $\mathrm{P}_{\mathrm{Ai}}=\left(\mathrm{R}_{\mathrm{Al}}+\mathrm{R}_{\mathrm{A} 2}\right) / 2$ & $\mathrm{~W}>\mathrm{L}$ and $\mathrm{i}, \mathrm{j}=1,2$ with $\mathrm{i} \neq \mathrm{j}$ \\
& $\mathrm{i}=1,2$ & $\mathrm{P}_{\mathrm{i}}=\mathrm{W}$ if $\mathrm{R}_{\mathrm{Ai}}>\mathrm{R}_{\mathrm{Aj}}$ \\
& & $\mathrm{P}_{\mathrm{i}}=\mathrm{L}$ if $\mathrm{R}_{\mathrm{Ai}}<\mathrm{R}_{\mathrm{Aj}}$ and $\mathrm{M}_{\mathrm{Ai}}, \mathrm{M}_{\mathrm{Aj}}>0$ \\
& & $\mathrm{P}_{\mathrm{i}}=(\mathrm{W}+\mathrm{L}) / 2$ if $\mathrm{R}_{\mathrm{Ai}}=\mathrm{R}_{\mathrm{Aj}}$ and $\mathrm{M}_{\mathrm{Ai}}, \mathrm{M}_{\mathrm{Aj}}>$ \\
& 0 \\
& & $\mathrm{P}_{\mathrm{i}}=0$ if $\mathrm{M}_{\mathrm{Ai}}=0$ \\
\hline
\end{tabular}

\footnotetext{
${ }^{4}$ More precisely, the optimal path is found by maximizing $\mathrm{R}_{\mathrm{Xi}}$ subject to $\left|\mathrm{H}_{\mathrm{Xi}}\right|+\left|\mathrm{V}_{\mathrm{Xi}}\right| \leq \mathrm{M}_{\mathrm{Xi}}$. Taking $\mathrm{H}_{\mathrm{Xi}}$ and $\mathrm{V}_{\mathrm{Xi}}$ to be continuous, maximization shows that $\mathrm{H}_{\mathrm{Xi}}$ and $\mathrm{V}_{\mathrm{Xi}}$ are linear in $\mathrm{M}_{\mathrm{Xi}}$, and thus that the optimal path in the $\left(\mathrm{H}_{\mathrm{Xi}}, \mathrm{V}_{\mathrm{Xi}}\right)$-plane is linear. By substituting $\mathrm{M}_{\mathrm{Xi}}$ for $\mathrm{H}$ and $\mathrm{V}$ in eq. (1), and differentiating the resulting equation with respect to $\mathrm{M}_{\mathrm{Xi}}$, the sign of the first and second derivatives can be established.
} 


\subsection{Conditions}

Table 2 shows the three conditions of the experiment. Besides payment schemes, also the relative remuneration of tasks $\mathrm{A}$ and $\mathrm{B}$ were varied by choosing different values for $\alpha$ in eq. (1). This is indicated in the table by the maximum result achievable on a task $\left(\mathrm{R}_{\mathrm{X}}{ }^{\mathrm{max}}\right)$. It is important to note that if there are two tasks with one task having, for instance, a maximum of 100 and the second of 50 and keeping all parameters the same (except $\alpha$ ), results on the first task are twice as high as on the second task for all combinations of $\mathrm{H}$ and $\mathrm{V}$.

Table 2. Experimental conditions

Condition 1: Piece Rate

Task A

\begin{tabular}{|c|c|c|}
\hline $\begin{array}{l}\text { Part } 1 \\
25 \\
\text { periods }\end{array}$ & $\begin{array}{l}\text { Individual } \\
\mathrm{R}_{\mathrm{A}}{ }^{\text {max }}=100\end{array}$ & $\begin{array}{c}\text { Individual } \\
\mathrm{R}_{\mathrm{B}}{ }^{\max }=\mathbf{5 0}\end{array}$ \\
\hline $\begin{array}{l}\text { Part } 2 \\
25 \\
\text { periods }\end{array}$ & $\begin{array}{l}\text { Individual } \\
\mathrm{R}_{\mathrm{A}}{ }^{\max }=\mathbf{5 0}\end{array}$ & $\begin{array}{c}\text { Individual } \\
\mathrm{R}_{\mathrm{B}}{ }^{\max }=\mathbf{5 0}\end{array}$ \\
\hline
\end{tabular}

Condition 2: Team

Task A

\begin{tabular}{|c|c|}
\hline $\begin{array}{c}\text { Individual } \\
\mathrm{R}_{\mathrm{A}}{ }^{\text {max }}=\mathbf{1 0 0}\end{array}$ & $\begin{array}{c}\text { Individual } \\
\mathrm{R}_{\mathrm{B}}{ }^{\mathrm{max}}=\mathbf{5 0}\end{array}$ \\
\hline $\begin{array}{c}\text { Team } \\
\mathrm{R}_{\mathrm{A}}{ }^{\text {axx }}=\mathbf{1 0 0}\end{array}$ & $\begin{array}{c}\text { Individual } \\
\mathrm{R}_{\mathrm{B}}{ }^{\text {max }}=\mathbf{5 0}\end{array}$ \\
\end{tabular}

Condition 3: Tournament

Task A

Task B

\begin{tabular}{|c|c|}
\hline $\begin{array}{l}\text { Individual } \\
\mathrm{R}_{\mathrm{A}}{ }^{\max }=100\end{array}$ & $\begin{array}{c}\text { Individual } \\
\mathrm{R}_{\mathrm{B}}{ }^{\max }=\mathbf{5 0}\end{array}$ \\
\hline $\begin{array}{c}\text { Tournament } \\
\mathrm{R}_{\mathrm{A}}{ }^{\max }=100 \\
\mathrm{~W}=135 \mathrm{~L}=\mathbf{3 5}\end{array}$ & $\begin{array}{c}\text { Individual } \\
\mathrm{R}_{\mathrm{B}}{ }^{\max }=\mathbf{5 0}\end{array}$ \\
\hline
\end{tabular}

The first part ( 25 periods) is the same in all conditions. In this part earnings in task A and task B only depend on the individual results. The maximum result renders 100 cents ( 1 guilder) in task A and 50 cents in task B. In the second part (25 periods) the B-tasks are the same in all conditions: payment is again based on the individual result and the maximum remains 50 cents. In the Piece-rate condition task $\mathrm{A}$ is the same as task B. Both are individually rewarded with a maximum result of 50 cents. In the second parts of the other two conditions subjects are randomly coupled, and these 2-person groups stay the same for all periods. In the Team condition the maximum result in task A is 100. In this set-up the individual return to a subject's work on task A is the same in parts 2 of the Piece-rate and Team conditions. For freeriders who are only concerned with their own payoffs, these conditions are equivalent. Within the Team condition, the return for the group of a subject's work in part 2 equals the individual return in part 1 . Thus, for cooperative players who are concerned with the group payoffs both parts are equivalent. 
In the Tournament condition, it is less obvious how to choose the payoffs to ensure comparability with the other conditions. Irrespective of the effort of both group members total earnings from task A are $\mathrm{W}+\mathrm{L}$, as long as both subjects make at least one move in A. This implies that the returns of own effort can not be equalized across conditions, as was the case above. To make a comparison possible, we calculated from the data the average actual earnings in task A for team remuneration ( 85 cents), and applied this average in the tournament. Earnings are then the same for both payment schemes, and effort levels can be compared.

In each period the parameter values for task A differ from those for task B (see eq. 1). The combinations of parameter values for the two tasks and the order in which they are presented are the same in all conditions. Each combination for A and B is used twice: once in part 1 and once in part 2 of the experiment. However, the order in which these combinations are presented is different for the two parts. In conditions 2 and 3 subjects were informed about the number of moves the subject with whom they were matched did for task A and the result this subject achieved for that task.

\subsection{Procedures}

The experiment consisted of 6 sessions, 2 for each condition. Subjects were recruited by announcements on bulletin boards in university buildings. 79 subjects participated; 27 in the piece-rate condition, 28 in the team condition, and 24 in the tournament condition. Each subject participated in only one session. Subjects were undergraduate students, mostly in Economics (68\%). A session took typically 1.5 hours, and the average earnings were 47.20 Dutch guilders (at that time approximately 25 US dollars). Subjects received instructions on the computer screen (see the Appendix). In addition, a handout with a picture of the typical screen (much like figure 1), including explanatory remarks, was distributed. After the instructions 5 practice periods were played. Except for the last, the practice periods were longer than the periods that were played for real, to let subjects get acquainted with the tasks, the keys to use and the computer screen. After the practice periods, subjects played the 25 periods of part 1. Subsequently, they received the instructions for part 2 (see the Appendix). After 2 practice periods, the 25 periods of this part were played. All periods for real took 50 seconds with a break of 15 seconds in between. Before being paid in private, the subjects filled out a short questionnaire. 


\section{Analysis and hypotheses}

In the natural setting of a job a worker would be interested in $\mathrm{P}_{\mathrm{i}}$, while the employer would be interested in $\mathrm{R}_{\mathrm{Ai}}$. In situations where payments of pairs of workers are interdependent (conditions 2 and 3), the employer would be interested in the total result of both workers which is given by $R_{A}=R_{A 1}+R_{A 2}$. As discussed in the introduction, a subject's result, $\mathrm{R}_{\mathrm{Ai}}$, depends on four factors: (a) the extent to which the subject exerts herself, which in the present context affects the total number of moves, (b) allocation of moves over A and B, (c) ability and (d) chance. Factors (a) and (b) determine the effort that is put in task A. In the experiment, we found no significant differences in the total number of moves per individual between payment schemes (parts 2 of the three conditions) $)^{5}$. This means that factor (a) does not play a role. Therefore, we can focus on the allocation of moves across tasks.

Obviously, we do not have control over ability. Ability may affect the transformation of moves into results and the total number of moves an individual can make in a period. For each subject, the number of moves and total result were added up over all 25 periods of part 1 in the three conditions. Results and number of moves prove to be highly correlated (.79). However, subjects differ considerably in the number of moves they are able to accomplish in a period of time. Since we saw that the total number of moves per individual does not significantly differ over the payment schemes, implying that the extent to which a subject exerts herself is constant, it is concluded that these differences between individuals are due to diverging ability ${ }^{6}$. Thus, $M_{i}$ reflects an individual's ability, while $M_{A i} / M_{i}$ reflects the individual's effort concerning task A.

We will now derive our hypotheses for the different payment schemes and the comparison of the schemes. Individual piece-rate pay serves as benchmark, and will be addressed first. Because per period task $\mathrm{A}$ is as difficult as task $\mathrm{B}$, rational subjects will equalize the marginal returns for both tasks (recall that the marginal return of a move is decreasing in the number of moves along the optimal path). This leads to our first hypothesis.

\footnotetext{
${ }^{5}$ This implies that in each condition the (expected) marginal return on a move is higher than the marginal (psychic) costs of that move. Subjects make the maximum number of moves they can manage in a period given the duration of the period and the lag between moves.

${ }^{6}$ Subjects are constrained by cognitive and motor abilities which set individual limits to the number of moves they can do in a period of time, try as they may. In the questionnaires they refer to themselves as being better/worse or faster/slower than others.
} 


\section{Hypothesis 1: earnings maximization under piece rates}

for piece rates, if $\mathrm{R}_{\mathrm{A}}{ }^{\mathrm{max}}=\mathrm{R}_{\mathrm{B}}{ }^{\max }$ as in condition 1 part $2, \mathrm{M}_{\mathrm{Ai}}=\mathrm{M}_{\mathrm{Bi}}$ and $\mathrm{R}_{\mathrm{Ai}}=\mathrm{R}_{\mathrm{Bi}}$.

In the team condition, the earnings from task A are the average of a subject's own result and that of another subject. Only half of the result achieved by a subject accrues to this subject. For rational, (narrowly defined) self-interested subjects it is a dominant strategy to regard only their own earnings. Thus, if for teams $\mathrm{R}_{\mathrm{A}}{ }^{\max }=2 * \mathrm{R}_{\mathrm{B}}{ }^{\text {max }}$ as in condition 2 part 2 , the dominant strategy implies that $\mathrm{M}_{\mathrm{Ai}}=$ $\mathrm{M}_{\mathrm{Bi}}$ and $\mathrm{R}_{\mathrm{Ai}}=2 * \mathrm{R}_{\mathrm{Bi}}$. To compare these results with those for individual piece rates, it is noted that the same individual incentives occur for piece rates if $R_{A}{ }^{m a x}=R_{B}{ }^{m a x}$. Again, equalization of the marginal returns in tasks $A$ and $B$ is expected, implying that $\mathrm{M}_{\mathrm{Ai}}$ will be of the same magnitude for both payment schemes. In public good experiments, subjects often do not behave in this way. Frequently, some level of cooperation occurs, bringing their earnings closer to the Pareto optimum. Therefore, as an alternative, we consider cooperative behavior where subjects take the joint earnings of themselves and their partners into account. In that case, incentives under team remuneration and piece rates are equalized if for piece rates also $\mathrm{R}_{\mathrm{A}}{ }^{\max }=2 * \mathrm{R}_{\mathrm{B}}{ }^{\mathrm{max}}$, as in part 1 of all three conditions. Consequently, under this hypothesis it is expected that the same number of moves in task A will be made for both payment schemes. Thus, the following alternative hypotheses about behavior in the team condition can be formulated.

\section{Hypothesis 2A: complete free-riding in teams}

If for team remuneration $\mathrm{R}_{\mathrm{A}}{ }^{\max }=2 * \mathrm{R}_{\mathrm{B}}{ }^{\max }$ and for piece rates $\mathrm{R}_{\mathrm{A}}{ }^{\max }=\mathrm{R}_{\mathrm{B}}{ }^{{ }^{m a x}}, \mathrm{M}_{\mathrm{Ai}}$ is the same for piece rates and teams, while $\mathrm{R}_{\mathrm{Ai}}$ for teams is twice as high as $\mathrm{R}_{\mathrm{Ai}}$ for piece rates.

\section{Hypothesis 2B: full cooperation in teams}

If for team remuneration and piece rates $\mathrm{R}_{\mathrm{A}}{ }^{\max }=2 * \mathrm{R}_{\mathrm{B}}{ }^{\mathrm{max}}, \mathrm{M}_{\mathrm{Ai}}$ and $\mathrm{R}_{\mathrm{Ai}}$ are invariant under these two conditions.

The analysis of the outcome of the rank-order tournaments is more complicated. This is, in particular, due to the repeated game which starts with subjects not knowing the abilities of their colleagues. The expected earnings of player 1 on task $A$, denoted by $\mathrm{EP}_{\mathrm{A} 1}\left(\mathrm{M}_{\mathrm{A} 1}, \mathrm{M}_{\mathrm{A} 2}\right)$, depend on the number of moves made by both players in task A. The expected earnings of player 1 on task $\mathrm{B}$ depend only on the number of moves she makes in task $\mathrm{B}, \mathrm{EP}_{\mathrm{B} 1}\left(\mathrm{M}_{\mathrm{B} 1}\right)$. Total expected earnings for player 1 are $\mathrm{EP}_{\mathrm{A} 1}\left(\mathrm{M}_{\mathrm{A} 1}, \mathrm{M}_{\mathrm{A} 2}\right)+$ $\mathrm{EP}_{\mathrm{B} 1}\left(\mathrm{M}_{\mathrm{B} 1}\right)$ and of player $2 \mathrm{EP}_{\mathrm{A} 2}\left(\mathrm{M}_{\mathrm{A} 1}, \mathrm{M}_{\mathrm{A} 2}\right)+\mathrm{EP}_{\mathrm{B} 2}\left(\mathrm{M}_{\mathrm{B} 2}\right)$. This defines a game. The solutions (Nash 
equilibria) of this game depend on the exact form of the functions $\mathrm{EP}_{\mathrm{A} 1}, \mathrm{EP}_{\mathrm{A} 2}, \mathrm{EP}_{\mathrm{B} 1}$ and $\mathrm{EP}_{\mathrm{B} 2}$. However, some general observations can be made.

Equal abilities. If players do not differ in ability, and both work only on task A, their expected earnings on task A will be 85 cents. Note from table 1 that this outcome does not require that players reach the maximum result $\mathrm{R}_{\mathrm{A}}{ }^{\max }$. If one player would switch to working only on task $\mathrm{B}$ the expected earnings are less than the maximum of 50 cents on task B, while they are 35 cents on task A (if she makes at least one move on task A). If both would start working on task B there would be an incentive for each of them to switch back to task A, in order to win the tournament. Thus, it is expected that both will concentrate effort on task A. This is also the case if players have approximately the same ability. The first moves on B give on average a very low result, because the probability a subject starts moving in a wrong direction on the $\mathrm{H}$ - or $\mathrm{V}$-dimension and gets a negative result is $50 \%$. Thus, if a subject decides to work on B, it must be for a sufficient number of moves (at least 3) to overcome this effect. If the difference in ability is small (for instance, leading to a difference of 3 or less moves on average), switching to B reduces the probability of winning the tournament strongly.

Unequal abilities. It is easy to see that if one of the players has a greater ability, she can spend some moves on task B and still do enough moves on A to make (almost) sure that she wins on that task. However, also for other reasons more moves can be expected on task B than in case of (approximately) equal ability. Suppose that player 1 is less capable than player 2 . If the difference in ability is sufficiently large, expected earnings from working only on task A are smaller than expected earnings from working only on task B (with the exception of one move on A to secure a price in the tournament). Consequently, it is more profitable for player 1 to work only on task B, if player 2 is working only on task A. However, when player 1 is working only on task B, it will be profitable for player 2 to spend some additional moves on task B (she will still win on task A). For these reasons, more moves on task B are expected than in case of (approximately) equal ability.

In the experiment subjects have to learn their relative ability by experience, since they do not have any advance information about their opponents. During the first few periods it is likely, therefore, that they believe their opponents to be of roughly the same ability, inducing them to start working only on task A. Once subjects perceive that they are of unequal ability, it is to be expected that the more (less) able player will relatively concentrate effort on task A (B). 


\section{Hypothesis 3A: competition in tournaments}

(a) In case of (approximately) equal abilities, both subjects work only on task A in all periods. Effort is higher than in case of individual piece-rate pay or team remuneration.

(b) In case of unequal abilities, subjects work only on task A in the initial periods. After a number of periods, both subjects start to allocate moves to task B, with the more (less) able worker relatively concentrating effort on task A (B). Total effort on task A will be lower than in case of equal abilities.

As to the Pareto-optimum, it is immediate that putting minimal effort in task A would be optimal. Nearly all effort can then be reserved for task B. Minimal effort implies that both subjects make one move in A. This would constitute cooperative behavior. Note that cheating is impossible, as after each period subjects are informed about the result and number of moves on A by the other. In this case both will win $50 \%$ of the tournaments on average.

\section{Hypothesis 3B: full cooperation in tournaments}

Independent of abilities, subjects do one move in task A, and further work on task B.

Bull et al. (1987) observed that outcomes vary much more in rank-order tournaments than in case of piece-rate pay. They attribute this to the strategic interaction that occurs in tournaments, which is absent in case of piece rates. One would expect the same to occur in our experiment. In the first place for the reason mentioned by Bull et al., and in the second place because of the diversity in abilities which leads to different optimal strategies in case of competitive behavior. Team remuneration does also entail strategic interaction, but free-riding as well as cooperative behavior is not affected by diversity in abilities. The next hypothesis follows.

\section{Hypothesis 4: variability of behavior}

In a rank-order tournament the standard deviations of $\mathrm{M}_{\mathrm{Ai}}$ and $\mathrm{R}_{\mathrm{Ai}}$ are larger than in case of team remuneration; also, the standard deviations are larger for team production than for piece rates.

\section{Results}

Before testing the hypotheses formulated in the previous section, we will look at some general findings. A preliminary issue is how subjects experienced the tasks they were asked to perform. The answers to the questionnaire give some insights. The questions took the form of statements with which subjects 
could agree or disagree. A 7-point scale was used. The table below summarizes the answers to the relevant questions:

Table 3. Mean scores of answers to questionnaire.

\begin{tabular}{|l|l|l|l|}
\hline statements & condition 1 & condition 2 & condition 3 \\
\hline I found the experiment boring & 3.5 & 2.9 & 2.5 \\
\hline I found the tasks heavy/tiring & 4.1 & 3.4 & 3.9 \\
\hline The experiment required me to work hard & 4.2 & 3.8 & 4.7 \\
\hline $\begin{array}{l}\text { In each period of the second part I found it exiting to } \\
\text { learn the outcome }\end{array}$ & $\begin{array}{l}\text { not } \\
\text { relevant }\end{array}$ & 4.8 & 6.0 \\
\hline
\end{tabular}

Note: scores refer to a 7 -point scale $(1=$ totally disagree, $7=$ totally agree; $4=$ indifferent $)$.

The work asked from subjects was on average considered neither to be heavy nor light. None of the conditions was considered boring. The tournament was the most exiting, followed by team production. Apparently, the interaction with another subject added spice to the work.

During the experiment it showed that subjects had no difficulty in understanding the tasks. The tasks did require specific abilities, though. Like in normal working situations, we found individual differences in ability. Most subjects improved their skills during the first part of the experiment. Figure 2 illustrates. Therefore, it is necessary to study not only total effort (number of moves) but also relative magnitudes, such as the allocation of moves over tasks ${ }^{7}$. Tables 4 and 5 give these measures for results and moves for the different conditions, parts and tasks. Figures 3 and 4 show the development of the average proportion of the number of moves and results for task $\mathrm{A}$ in part 2 , for the three conditions.

\footnotetext{
${ }^{7}$ In part 1 the proportion of moves on A (and thus on B) did not change in the course of the experiment. For instance, in the first 12 periods the mean of the moves in A per period is .727, while in the last 12 periods the mean is .725 . We also redid the relevant analyses with exclusion of the first 10 periods of part 1 and the corresponding periods of part 2 . Outcomes were not affected.
} 


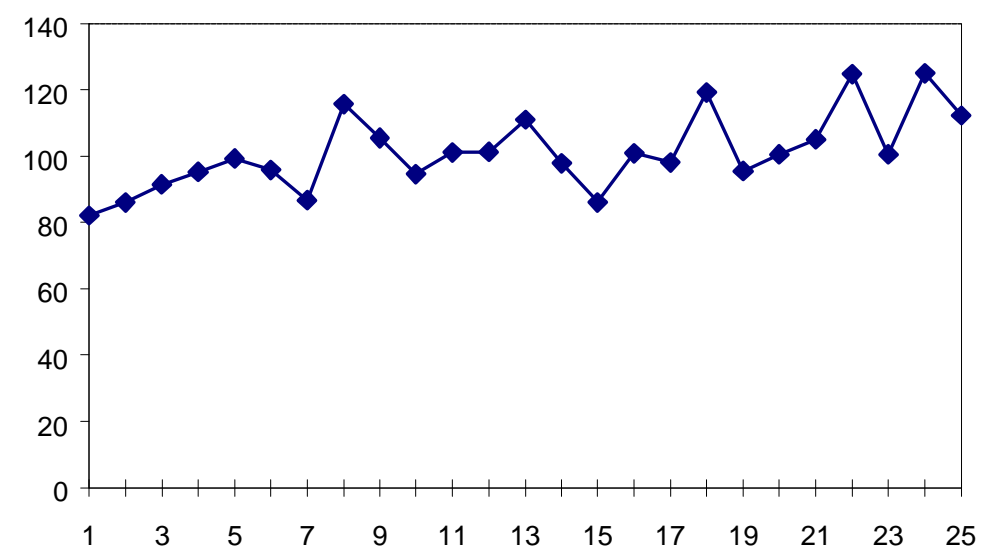

Figure 2. Mean earnings in part 1 by period, in cents.

Table 4. Mean of result and number of moves, by condition, part and task.

$\begin{array}{lll}\text { Piece Rate } & \text { Team } & \text { Tournament }\end{array}$

\begin{tabular}{|ll|cc|cc|cc|}
\cline { 3 - 8 } \multicolumn{1}{l|}{} & Task A & Task B & Task A & Task B & Task A & Task B \\
\hline Result & & & & & & & \\
& Part 1 & 81.67 & 19.97 & 81.81 & 16.99 & 85.05 & 18.59 \\
& Part 2 & 36.93 & 31.28 & 84.42 & 20.00 & 90.03 & 3.80 \\
\hline Moves & & & & & & & \\
& Part 1 & 19.96 & 8.73 & 19.88 & 7.44 & 21.54 & 7.83 \\
& Part 2 & 16.17 & 13.53 & 20.12 & 8.32 & 27.72 & 2.22 \\
\hline
\end{tabular}

Table 5. Mean of result and number of moves as percentage of total result and total number of moves, by condition, part and task.

Piece Rate

Team

Tournament

\begin{tabular}{|ll|ll|ll|ll|}
\cline { 3 - 8 } \multicolumn{1}{l|}{} & Task A & Task B & Task A & Task B & Task A & Task B \\
\hline Result & & & & & & & \\
& Part 1 & $81.13 \%$ & $18.87 \%$ & $83.55 \%$ & $16.45 \%$ & $82.56 \%$ & $17.44 \%$ \\
& Part 2 & $54.85 \%$ & $45.15 \%$ & $81.36 \%$ & $18.64 \%$ & $93.23 \%$ & $6.77 \%$ \\
\hline Moves & & & & & & & \\
& Part 1 & $70.06 \%$ & $29.94 \%$ & $73.68 \%$ & $26.32 \%$ & $73.49 \%$ & $26.51 \%$ \\
& Part 2 & $54.89 \%$ & $45.11 \%$ & $71.28 \%$ & $28.72 \%$ & $92.39 \%$ & $7.61 \%$ \\
\hline
\end{tabular}




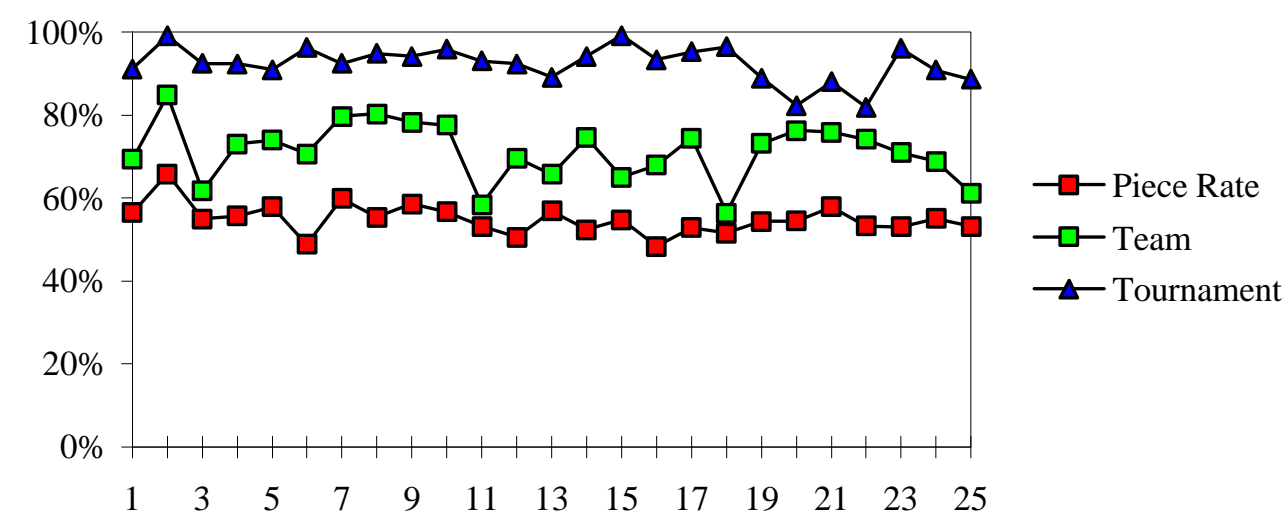

Figure 3: Average proportion of moves in task A, part 2, by period and condition.

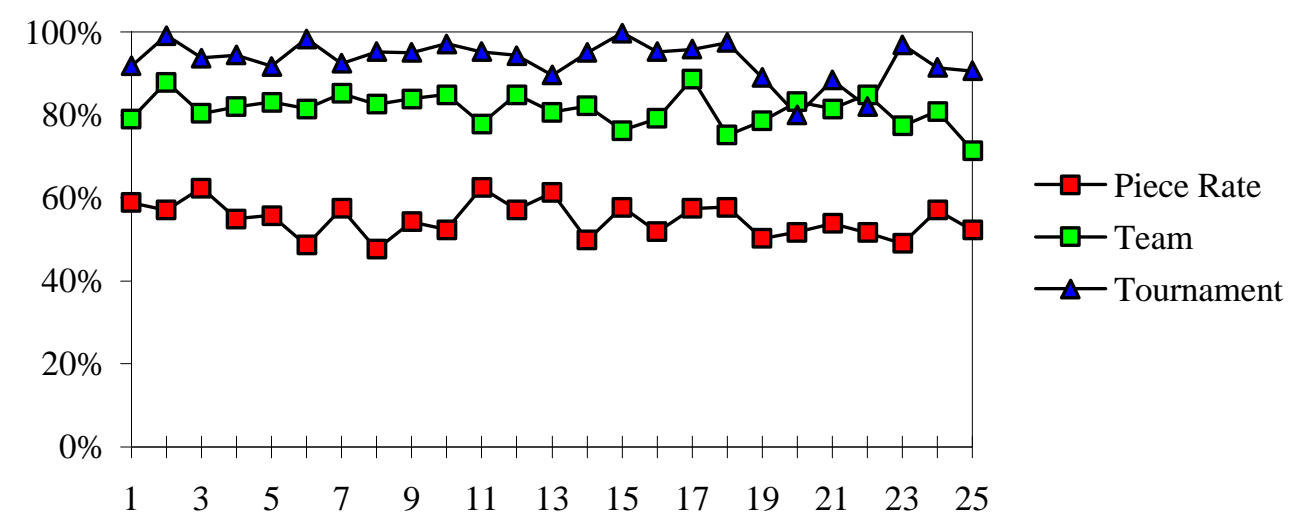

Figure 4: Average proportion of the result on task A, part 2, by period and condition.

It is noted that parts 1 of the three conditions do not differ with respect to the number of moves and the results. Also, there are no statistically significant differences in the total number of moves in part 2 for the three conditions. Regarding the hypotheses formulated in section 3 the following results are obtained. 


\section{Hypothesis 1: Earnings maximization under piece rates}

We compare task A and task B of the Piece-Rate condition, part 2 (see table 4). Although the tasks are equivalent $\left(R_{A}{ }^{\max }=R_{B}{ }^{m a x}\right)$, subjects make more moves in $A$ than in $B$ on average (16.2 vs. 13.5). The average result for task $\mathrm{A}$ is also higher than for B (36.9 vs. 31.3). These differences are highly significant (Wilcoxon, with subjects as unit of observation: for results $p=.0000$, for moves $p=.0002)^{8}$. Apparently, subjects tend to work too long on a task. As most start with task A, they make too many moves in A. On the basis of these results we have to reject hypothesis 1 . As the same phenomenon is likely to occur in the other conditions, payment schedules will be evaluated against each other.

\section{Hypothesis 2A: complete free-riding in teams}

In part 2 of the Team condition, individual maximum earnings are 50 in task $\mathrm{B}$ and, for own moves, also 50 in task $A\left(R_{A}{ }^{m a x}\right.$ is 100 , but earnings are the average of the results of the pair members). Complete free-riding would mean that subjects equally divide their effort between task A and task B. As seen above, however, even in the Piece-Rate condition subjects tend to spend more effort on task A. Therefore, the correct comparison is with the behavior of subjects in that condition. Behavior in both conditions would be the same if all subjects in the Team condition free-ride. However, as tables 4 and 5 show, subjects in the Team condition make more moves in A (20.1 vs. 16.2), also proportionally (71.3\% vs. $54.9 \%)$. Their results on A are more than twice as high $(84.4$ vs. $73.9=2 * 36.93$; in relative terms, $81.4 \%$ vs. $54.9 \%$ ). These differences are highly significant (Mann-Whitney, with groups as unit of observation, $\mathrm{p}=0.0000$ ). Consequently, hypothesis $2 \mathrm{~A}$ is rejected.

\section{Hypothesis 2B: full cooperation in teams}

If subjects in the Team condition would go for the Pareto-optimum, they would invest as much effort in the team-task, task A in part 2, as in the individual task, task A in part 1, given the biases they revealed in part 1. To compare the first and second part, we will look at relative instead of absolute levels of effort to filter out learning effects (see footnote 7). Subjects spend on average $73.7 \%$ of their moves on task $\mathrm{A}$ in the first (individual piece rate) part and $71.3 \%$ in the second (team) part of the experiment (see table 5). The relative result for task A also drops slightly from $83.6 \%$ in part 1 to $81.4 \%$ in part 2 .

\footnotetext{
${ }^{8}$ The parameter combinations were drawn randomly for tasks A and B. Optimal choices under full information would result in $51.6 \%$ of the moves to be in A (instead of the hypothesized 50\%). Correcting for this small difference, we still find a significant effect $(\mathrm{p}=.0288)$.
} 
These differences are not significant, however (Wilcoxon, groups as unit of observation). Thus, hypothesis $2 \mathrm{~B}$ cannot be rejected on the basis of these results.

Table 6. Percentage of moves in task A by pair members for parts 1 and 2 of the Team condition.

\section{Part 1}

\begin{tabular}{lllll} 
Group & \multicolumn{1}{c}{$\mathbf{S}_{\mathbf{1}}$} & \multicolumn{1}{c}{$\mathbf{S}_{\mathbf{2}}$} & \multicolumn{1}{c}{$\mathbf{S}_{\mathbf{1}}$} & \multicolumn{1}{c}{$\mathbf{S}_{\mathbf{2}}$} \\
201 & 86.06 & 99.16 & 79.51 & $67.16^{* * *}$ \\
202 & 72.80 & 72.31 & $\mathbf{8 3 . 6 2 * *}$ & $60.07^{*}$ \\
203 & 70.62 & 71.29 & 75.01 & 73.61 \\
204 & 71.48 & 64.72 & 71.14 & $\mathbf{6 9 . 9 6 *}$ \\
205 & 64.72 & 70.73 & 62.60 & 66.58 \\
206 & 63.48 & 70.88 & 67.31 & 70.57 \\
207 & 88.09 & 84.42 & $68.74^{* * *}$ & $62.27 * *$ \\
301 & 72.91 & 70.51 & 71.63 & $\mathbf{7 7 . 2 4} *$ \\
302 & 60.48 & 74.95 & $\mathbf{7 3 . 9 7 * * *}$ & $\mathbf{8 9 . 5 0 * * *}$ \\
303 & 63.96 & 87.69 & 64.42 & 86.59 \\
304 & 84.36 & 68.17 & $\mathbf{9 4 . 6 0 * *}$ & $62.68 *$ \\
305 & 59.81 & 54.14 & $\mathbf{6 9 . 1 1 * * *}$ & $\mathbf{6 6 . 2 1} * * *$ \\
306 & 83.19 & 67.25 & $69.56^{* *}$ & $55.85^{* * *}$ \\
307 & 71.64 & 93.18 & 69.21 & $67.09 * * *$
\end{tabular}

Note: pair members are denoted by $S_{1}$ and $S_{2}$. Italics denote a statistically significant decrease of the number of moves in task $\mathrm{A}$, a bold printed number indicates a statistically significant increase. (Wilcoxon test, $* \mathrm{p}<.05, * * \mathrm{p}<.01, * * * \mathrm{p}<.001^{9}$ ).

This result suggests that subjects are very cooperative in the team task, and that their behavior does not change from part 1 to part 2. A different picture emerges if we look at the data on the individual level. As shown in table 6,8 of the 28 subjects significantly reduced and another 8 significantly increased their proportion of moves in task $\mathrm{A}^{10}$. The changes for the other 12 subjects ( 8 decreases, 4 increases) are not statistically significant.

Free-riding does occur. It occurs in six groups, in two of which both individuals reduce their effort. Increases of effort occur in six groups, with both subjects increasing their effort in two groups. In 4

\footnotetext{
${ }^{9}$ Per subject comparison of the same parameter combinations of tasks in part 1 and part 2 .

${ }^{10}$ For each subject a Wilcoxon test was calculated, with 25 paired observations (note that each pair of tasks was used once in part 1 and once in part 2).
} 
groups the number of moves of both group members together declined and thus fell below the optimum for the team, taking biases into account, while in 8 groups it increased and became higher than the team optimum. Four groups decreased and three groups increased their number of moves significantly (Wilcoxon tests, $\mathrm{p}<0.05$ ). In both situations an inefficiency occurs.

A further point of interest is the end-effect that typically occurs in public good experiments. Contributions typically fall rapidly towards the free-riding outcome in the last rounds. While some decline in effort in the last five periods can be observed in figures 3 and 4, this decline falls within the range of fluctuations in earlier periods. The possible causes are discussed in section 5.

\section{Hypotheses 3A (a) and (b): competition in tournaments}

Before distinguishing (approximately) equal-ability and unequal-ability groups, we study all groups together. To test the hypotheses we compare the effort of subjects on task A in parts 1 and 2 of the Tournament condition. Again, we examine proportions of moves and results. Table 5 shows that, overall, the number of moves in A is dramatically higher in the tournament part (92.4\%) than in the individual (piece-rate) part (73.5\%). As a consequence, the results for task A also increase $(93.2 \%$ vs. $82.6 \%$ ). Both effects are statistically significant (Mann-Whitney, groups as unit of observation, $\mathrm{p}<.0001)$. These effects are general: in 11 of the 12 groups the (relative) number of moves on A and the (relative) result for $\mathrm{A}$ is higher in part 2 than in part 1. Only one subject reduced effort significantly, while three subjects did not alter their effort. All others increased their effort in A significantly ${ }^{11}$. Figure 5 gives the average relative number of moves in task A for all periods. There is no substantial decrease of moves in A over time.

11 Overall, this behavior makes sense, as the data show that the first 1, 2, 3, 4 or 5 moves in task B lead to an average gain of .1, 2.3, 5.6, 9.2 and 12.9 cents. If the winner in task A had made 1, 2, 3, 4 or 5 moves less, she would have lost, respectively 9, 13.6, 18.4, 23.6 and 26.1 cents on task A on average. 


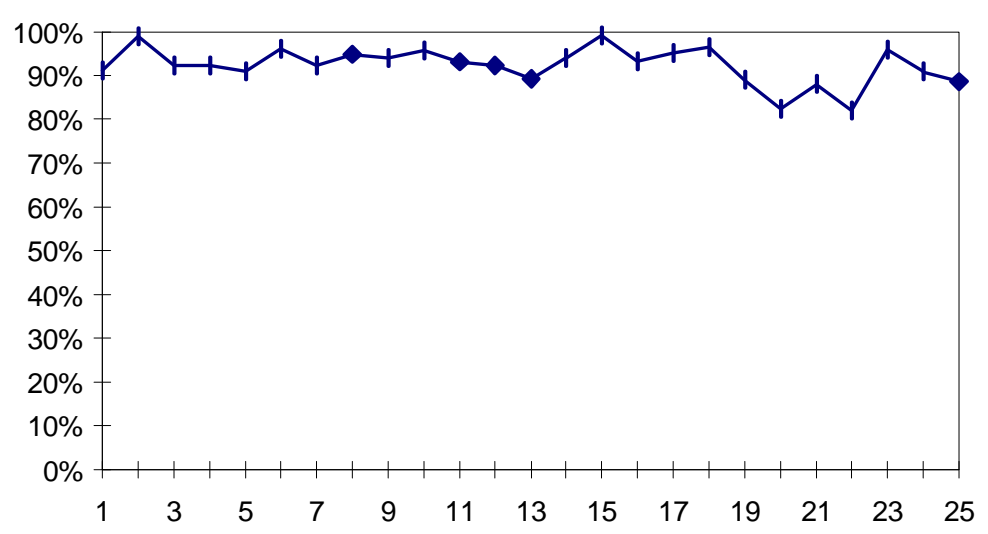

Figure 5. Relative number of moves on task A by period in part 2 of the Tournament condition.

The relative number of moves is also much higher in the tournaments than for team rewards $(92.4 \%$ vs. 71.3\%). Again, these differences are highly significant (Mann-Whitney, groups as unit of observation, $\mathrm{p}<.0001)$.

Of the 24 subjects, 12 fully concentrated their effort on task A, only switching to B if in A they reached the maximum of 100, in all or all but one periods. Table 7 shows that when subjects tend to spend all their moves on task A (e.g. 701, 703, 704), their abilities are very equal (resulting in a large number of draws and/or equal number of wins). To study the effect of individual differences in ability, we select first the groups in which the sum of results for tasks $\mathrm{A}$ and $\mathrm{B}$ in part 1 do not differ significantly between the group members. Out of 12 groups 8 are homogeneous in this sense. With three exceptions all subjects in these groups increased the number of moves in A and, consequently, their result on A, relative to part $1 ; 8$ out of the 16 subjects exclusively worked on task A, whereas 13 did so in 20 or more periods. Second, only in one of the four non-homogenous groups we do not find a statistically significant increase of the number of moves and result on task A, relative to part 1 . In the other groups the number of moves in A went up drastically. 4 of the 8 subjects worked only on B if they had reached 100 on A in all or all but one periods (5 did so in 20 or more periods). The relative number of moves on task A did not decline in the course of part 2. 
Table 7. Effort in tournaments per group and subject

$\begin{array}{lllll}\text { Part } 1 & \text { Part } 1 & S_{1} & S_{2}\end{array}$

\begin{tabular}{|c|c|c|c|c|c|c|c|c|c|c|}
\hline Group & $\mathbf{S}_{1}$ & $\mathbf{S}_{2}$ & & $\mathbf{S}_{1}$ & $\mathbf{S}_{2}$ & $\mathbf{S}_{1}$ & $\mathbf{S}_{2}$ & wins & draw & wins \\
\hline 601 & 107.19 & 109.04 & - & 76.41 & 68.99 & 44.14 & 92.98 & 5 & 0 & 20 \\
\hline 602 & 100.06 & 105.53 & $*$ & 84.38 & 70.97 & 96.77 & 97.21 & 5 & 3 & 17 \\
\hline 603 & 109.49 & 107.92 & - & 60.53 & 70.86 & 92.88 & $78.76 \mathrm{~ns}$ & 15 & 5 & 5 \\
\hline 604 & 112.57 & 109.87 & - & 63.17 & 71.22 & 94.29 & 99.34 & 3 & 5 & 17 \\
\hline 605 & 106.61 & 91.85 & $* * *$ & 76.79 & 83.36 & 97.79 & $72.48 \mathrm{~ns}$ & 22 & 0 & 3 \\
\hline 606 & 85.86 & 100.06 & $* * *$ & 81.44 & 69.56 & 94.29 & 89.73 & 17 & 1 & 7 \\
\hline 701 & 103.54 & 106.09 & - & 80.12 & 79.15 & 100 & 100 & 10 & 2 & 13 \\
\hline 702 & 108.71 & 114.17 & $*$ & 71.42 & 60.60 & 99.61 & 94.89 & 7 & 4 & 14 \\
\hline 703 & 95.88 & 99.47 & - & 82.36 & 57.15 & 97.92 & 100 & 15 & 4 & 6 \\
\hline 704 & 103.98 & 101.22 & - & 73.07 & 68.55 & 99.86 & 100 & 8 & 4 & 13 \\
\hline 705 & 100.66 & 97.85 & - & 80.83 & 83.27 & 97.98 & $85.82 \mathrm{~ns}$ & 17 & 3 & 5 \\
\hline 706 & 106.40 & 103.24 & - & 68.29 & 81.36 & 92.28 & 98.31 & 3 & 5 & 17 \\
\hline
\end{tabular}

Note: for each group (column 1) in the Tournament condition the sum of results for tasks A and B in part 1 are displayed for both group members, $S_{1}$ and $S_{2}$ in columns 2 and 3. Column 4 shows whether the differences in total results in part 1 are statistically significant (Wilcoxon test, * $\mathrm{p}<.05$, ** $\mathrm{p}<.01$ *** $\mathrm{p}<.001$ ). Columns 5-8 show the percentage of moves in task A for both group members in the two parts. If printed in bold (italics), a subject increased (decreased) the proportion of moves on task A significantly. The absence of significant change is indicated by "ns". The last three columns show how often each subject won or a draw occurred.

Of course, subjects did not have the information about relative ability that we have used here. Their knowledge could only be based on their relative performance in previous periods, and thus could only evolve gradually. One would expect that the number of periods a subject won the tournament in for instance the previous ten periods, would affect behavior in later periods. Calculations show that if subjects won in $20 \%$ or less of the previous 10 periods $^{12}$, they worked only on A in $78 \%$ of the cases. If they won in $20-80 \%$ of periods, they worked only on A in $87 \%$ of the cases. If they won in $80 \%$ or more of the periods, they exclusively worked on A in $90 \%$ of the cases. While the least able subjects indeed reduced their effort in later periods, the reduction is very small. The motivation of these subjects, who lose most of the time but keep investing most of their effort in task A, is puzzling. It seems they have difficulty in admitting they were less competent, and giving up the fight. By continuing to work mostly on A, they forced their opponents not to drop their effort on A. We conclude that hypothesis $3 \mathrm{~A}(\mathrm{a})$ is confirmed by the data, whereas hypothesis $3 \mathrm{~A}(\mathrm{~b})$ is rejected. 


\section{Hypothesis 3B: full cooperation in tournaments}

Fully cooperative behavior would prescribe that subjects put nearly all effort in task B and win with equal probability the tournaments by putting minimal equal effort in A. None of the groups display this behavior. Thus, hypothesis 4 is rejected.

It is striking that subjects behaved very differently in the conditions that entailed interaction. In the tournaments they did not try to cooperate, though this would have been very profitable. Admittedly, cooperation is harder to achieve than in the Team work condition, as the temptation to defect and win the tournament is much larger than in the case of team rewards. Apparently, subjects were drawn into the tournament, and played it with great vigor. A different state of mind is also reflected in the answers to the questionnaire (see table 8). In the Tournament condition winning was much more important than in the Team condition. In the questionnaire, we also asked them to describe their strategies. In the Tournament condition none of subjects expressed attempts to achieve cooperation. Of the 24 subjects 15 said they put all effort in task A in every period. Only three followed the type of strategy hypothesized in section 3 for the less able player, after realizing they were less 'good' or 'less' fast (as they described themselves) than their opponent. One subject realized towards the end of the 25 periods that he had no chance of winning and shifted to only working on task B in the very last periods, while others did not realize this at all or kept hoping for a recovery. In the questionnaire some subjects showed regret of not working on task B.

Table 8. Mean scores of answers to the questionnaire.

\begin{tabular}{|l|l|l|l|}
\hline statements & condition 1 & condition 2 & condition 3 \\
\hline $\begin{array}{l}\text { in part 2 my earnings were less important for me than } \\
\text { to win from the other participant }\end{array}$ & - & 2.5 & 3.5 \\
\hline $\begin{array}{l}\text { my objective in part 2 was to earn together with the } \\
\text { other participant as much money as possible }\end{array}$ & - & 4.7 & 1.3 \\
\hline
\end{tabular}

Note: scores refer to a 7 -point scale $(1=$ totally disagree; $7=$ totally agree; $4=$ indifferent $)$.

\footnotetext{
${ }^{12}$ A draw is counted as half a win.
} 


\section{Hypothesis 4: variability of behavior}

Table 9 gives means and standard deviations of the results for task A in parts 1 and 2 of the three conditions. Note that in order to make the standard deviations comparable, the standard deviation of part 2 in the Piece-Rate condition needs to be multiplied by 2 . We find that behavior in tournaments is much more variable than in the other two conditions. This result is statistically highly significant. There is no such difference between the Piece-Rate and Team condition. Thus, the hypothesis is partly rejected. An important factor is that in the tournaments a small number of subjects switched nearly completely to working only on task B in a substantial number of periods (one subject did that in 14 periods, another in 8 periods, while the third did that in 5 periods). In sum, the presence of strategic interaction as such does not explain the results, as this would have required higher variability in the Team condition than observed. The cause seems to lie in the structure of tournaments, which brings some subjects to alternate between working exclusively on A and exclusively on B.

Table 9. Mean and standard deviation (SD) of the results for task A in the three conditions.

Piece rate

Team

Tournament

\begin{tabular}{|l|ll|ll|ll|}
\cline { 2 - 7 } \multicolumn{1}{c|}{ Task A } & Mean & SD & Mean & SD & Mean & SD \\
\hline Part 1 & 81.67 & 14.57 & 81.81 & 13.83 & 85.05 & 12.67 \\
Part 2 & 36.93 & 7.92 & 84.42 & 13.03 & 90.03 & 22.81 \\
\hline
\end{tabular}

\section{Discussion}

Our experimental results suggest that piece rate and team payment schemes motivate workers to the same extent, while relative pay (tournaments) leads to higher effort on average. From the perspective of an employer, relative payment schemes would therefore be superior. A drawback of relative pay is, however, the larger variability of effort compared to the other schemes. From the perspective of a worker the benefits from the extra effort provided under relative pay fall short of the opportunity costs (in our case the benefits of activities in the boss' time for oneself), and the resulting effort level is thus inefficient. When abilities of workers differ, especially the behavior of less able workers drives up effort. They generally do not seem (willing) to realize that they have little chance of winning the 
tournaments and that it would be more profitable to them to concentrate on the other (individual) task. This result is in line with what Bull et al. (1987) found.

The finding that piece rates and team pay bring about the same effort levels is surprising. While freeriding does occur in some teams, many subjects provide more effort than in case of individual pay. This result differs from the findings of the effort experiment by Nalbantian and Schotter (1997) and of many public good experiments in which subjects have to allocate budgets to private and public accounts. In these experiments substantial free-riding is found. Contributions of work and money seem to have different consequences ${ }^{13}$. In case teams are really required to work, there apparently exist motivations which compensate for the tendency towards free-riding. Such motivations could stem from peer pressure and/or (friendly) competition among team members about who is more competent, although other aspects are likely to play a role as well (see section 4). Interestingly, with team rewards cooperation prevails, whereas in tournaments cooperative behavior does not occur at all. This points in the direction that in both conditions subjects try to 'win' by producing more than their group members. In the team condition this behavior promotes cooperation, while in tournaments it reduces cooperation. It is noted that this finding is suggestive for the importance of doing real-effort experiments when work effort, including voluntary contributions of work to public goods, are investigated. Note also that theories which do not take into account factors such as a desire to outperform others irrespective of monetary gain, do not fare very well. Our results may help explain why team work/remuneration is a popular and widely used incentive system, despite the theoretical predictions and the evidence from the aforementioned experiments that team pay is inferior to individual pay.

The choice of payment scheme has consequences for social relations in the workplace. In the questionnaire subjects were asked whether - if the experiment were to be repeated - they would prefer to continue working together with the person they were matched with in the second part or whether they would prefer to be coupled with a randomly chosen other participant. It is not surprising that in the Tournament condition subjects were only happy to continue if their opponents were less good than they themselves. In the Team condition subjects were generally satisfied with their partners and wanted to continue with them. However, in cases where co-workers contributed little to the production of the team

\footnotetext{
${ }^{13}$ Our results differ also from those of the field experiment by Erev et al. (1993) which was briefly discussed in the introduction. In their team-work condition teams consisted of four subjects. Although the results are, therefore, not fully comparable, the discrepancy is striking. In our experiment subjects received frequent and precise feedback about the performance of their partners, while in the experiment by Erev et al. feedback was less frequent and less accurate. The main difference between the experiments is, however, the type of task: fatiguing, dull manual work in their case versus cognitively demanding and less dull work in our case.
} 
subjects expressed a desire to have no future interaction. A direct consequence would be that if workers are involved in the recruitment of new employees they would have very different incentives under both payment schemes. With relative pay, they would try to have low ability workers recruited, while with team work they would prefer workers of high ability. Relative pay creates 'adverse selection' problems which would be particularly acute in case of current workers (and bosses) with low abilities. In addition, it seems that tournaments and team work lead to very different social dynamics. While team work leads to positive sentiments towards others among equally performing workers, tournaments do not seem to foster such sentiments at all.

\section{References}

Bridger, R.S. and Long, L. (1984). Some cognitive aspects of interface design in a two-variable optimization task. International Journal of Man-Machine Studies 21, 521-539.

Bull, C., Schotter, A. and Weigelt, K. (1987). Tournaments and piece rates: an experimental study. Journal of Political Economy 95, 1-33.

Erev, I., Bornstein, G. and Galili, R. (1993). Constructive intergroup competition as a solution to the free rider problem: a field experiment. Journal of Experimental Social Psychology 29, 463-478.

Fehr, E. Kirchsteiger G. and Riedle, A. (1993). Does fairness prevent market clearing? an experimental investigation. Quarterly Journal of Economics 108, 437-459.

Kandel, E. and Lazear, E.P. (1992). Peer pressure and partnerships. Journal of Political Economy 100, 801-817.

Knoeber, C.R. and Thurman, W.N. (1994). Testing the theory of tournaments: an empirical analysis of broiler production. Journal of Labor Economics 12, 155-179.

Lazear, E.P. (1996). Performance pay and productivity. Working Paper 5672, NBER.

Lazear, E.P. (1996). Personnel economics. MIT Press, Cambridge.

Ledyard, J.O. (1995). Public goods: a survey of experimental results. in: Kagel, J.H. and Roth, A.E. The handbook of experimental economics. Princeton University Press, Princeton.

Nalbantian, H.R. and Schotter, A. (1997). Productivity under group incentives: an experimental study. American Economic Review 87, 314-341.

Pingle, M. (1995). Imitation versus rationality: an experimental perspective on decision making. The Journal of Socio-Economics 24, 281-315. 
Pingle, M. (1997) Submitting to authority: its effect on decision making. Journal of Economic Psychology 18, 45-68.

Prendergast, C. (1996). What happens within firms? A survey of empirical evidence on compensation policies. Working Paper 5802, NBER.

Schotter, A. and Weigelt, K. (1992). Asymmetric tournaments, equal opportunity laws, and affirmative action: some experimental results, Quarterly Journal of Economics, 511-539. 


\section{Appendix. Computerized instructions (translated from Dutch)}

[In all three conditions part 1 of the experiment is the same.]

\section{INSTRUCTIONS PART 1}

The experiment in which you are going to participate is about work.

It consists of two parts that will each take half an hour.

\section{Part 1}

Part 1 is an experiment that does not involve interaction with other participants. This means that your earnings in this part depend only on your own results. In this part we will ask you to perform simple tasks on the computer.

Part 1 consists of 25 periods of 50 seconds each, with breaks of 15 seconds in between.

In each period two tasks are offered. You can work in turns on these tasks. Both earn you money. You may choose the task to start with and, subsequently, you may switch from the one to the other whenever you like.

Each task consists of searching for a value that is as high as possible. This value depends on two variables $\mathrm{H}$ (Horizontal) and V (Vertical). High values can be found by varying $\mathrm{H}$ and/or V. There is always one maximum value. You can visualize this maximum as the top of a single-peaked mountain. More than one peak with valleys in between does not occur. The mountain becomes less steap, the closer you come to its top.

$\mathrm{H}$ and $\mathrm{V}$ can vary between -25 and 25 .

In each period you start your search at $\mathrm{H}$ is 0 and $\mathrm{V}$ is 0 . The value is then also 0 . In steps of $1 \mathrm{H}$ or $\mathrm{V}$ can be varied. The highest value that can be reached is 100 for task 1 and 50 for task 2. However, depending on your choice of $\mathrm{H}$ and $\mathrm{V}$, you may get lower values and even negative values. For both tasks, the value you have reached at the end of a period, is your result in that period.

Your results in points in a period are equal to the value reached at the end of the period. Your earnings in a period depend on your results. In case of a positive result, you will receive money. A negative result will cost you money. Every point is worth money, according to the exchange rate 100 points is 1 guilder.

The maximum value for task 1 is 100 in all periods, while the maximum for task 2 is always 50 . In both tasks you will always start with $\mathrm{H}$ is 0 and $\mathrm{V}$ is 0 . The value is than 0 . In the two tasks the maximum value is reached at different combinations of values of $\mathrm{H}$ and $\mathrm{V}$.

In the handout that will now be distributed the computer screen is explained. We will start now with 5 test periods to familiarize you with the tasks.

If you want to read the instructions again, press the PageUp button. If not, press K.

As soon as everybody is ready, we will begin with the 5 test periods. In these test periods, you cannot earn money.

It is noted that - after you have changed $\mathrm{H}$ or $\mathrm{V}$ - you can only alter $\mathrm{H}$ or $\mathrm{V}$ again after one and a half seconds.

In the first four test periods you will get more time than in the experiment itself. In the fifth period you will have the same amount of time as in the experiment. If you want to ask a question, please raise your hand.

[After the 5 test periods]

The test periods have finished. We now start with period 1 of the first part. You can now earn money. 
Only your own results determine your earnings. The highest value you can reach is 100 for task 1 and 50 for task 2.

Note that a period lasts 50 seconds. Time starts running, as soon as the question which task you want to start working on appears on your screen.

[After 25 periods]

The first part has finished.

\section{INSTRUCTIONS PART 2 \\ [CONDITION 1: INDIVIDUAL PIECE RATE]}

We will now start with the second part of the experiment. Just as part 1, part 2 consists of 25 periods of 50 seconds each with a break of 15 seconds in between.

The tasks have the same character as those of part 1. Only your own results determine your earnings.

There is, however, an important difference with part 1 . The highest value you can reach

is 50 both in task A and in task B.

Two test periods will follow now. In these test periods you cannot earn money. We will start as soon as everybody is ready.

The highest value you can reach is 50 at task $\mathrm{A}$ and 50 at task $\mathrm{B}$. The exchange rate is again 100 points equal 1 guilder.

If you want to ask a question, please raise your hand.

[after the 2 test periods]

We will start now with period 1 of the second part. There will be 25 periods. You can earn money from now on.

[after 25 periods]

The experiment has finished. Please, remain seated, and fill out the questionnaire that will be distributed now. When you are ready, you will be asked one by one to go to the next room to receive your earnings.

\section{[CONDITION 2: TEAM WORK]}

We will now start with the second part of the experiment. Just as part 1, part 2 consists of 25 periods of 50 seconds each, with a break of 15 seconds in between.

The tasks have the same character as those of part 1. Again, task B concerns only yourself. Your own result alone determines your earnings.

However, the earnings from task A differ from those in part 1. Your earnings from task A are not only determined by your own results, but also by the result of another participant ("the other"). In turn, the earnings of this other participant are determined in part by your result at task A.

Task A consists of team work. You will be matched with another participant. During the whole of part 2, you will be coupled with the same person. Your earnings from task A are the average of your own result and the result of the other.

After each period you will be informed about the number of moves and results of the other for task A. The other will see your number of moves and results for task A.

The highest value that you can reach at task A is 100 . The highest value at task B is 50 .

Assume that at task A you reach a value of 40 (this is your result) and the other reaches a value of 80 (this is the result of the other). You and the other will each earn the average of your and the other's result. In this example you will earn 60 points. The earnings of the other are also 60 points. 
The maximal earnings in task A are reached if you both achieve a result of 100 .

Your earnings are then 100 points. The other earns the same amount.

Your total earnings in a period are the sum of your earnings in task A and B. Your earnings in a period are thus 150 points at the maximum. The exchange rate is again 100 points equal 1 guilder.

The tasks that will be presented to you have exactly the same character as those in part 1, and they will also be presented in the same way. On your screen only the table giving the results is different.

In the handout that will now be distributed, a summary of the instructions is given.

To clarify matters 2 test periods will follow now. In these test periods you cannot earn money.

If you want to ask a question, please raise your hand.

If you want to study the instructions again, use the PageUp-button. If not, press K.

As soon as everybody is ready, the 2 test periods will start.

[after the 2 test periods: as above]

[after 25 periods: as above.]

\section{[CONDITION 3: RANK-ORDER TOURNAMENT]}

We will now start with the second part of the experiment. Just as part 1, part 2 consists of 25 periods of 50 seconds, each with a break of 15 seconds in between.

The tasks have the same character as those of part 1. Again, task B concerns only yourself. Your own result alone determines your earnings.

However, the earnings from task A differ from those in part 1. Your earnings from task A are not only determined by your own results, but also by the result of another participant ("the other"). In turn, the earnings of this other participant are determined in part by your result at task A.

For task A you will be matched with another participant. During the whole of part 2, you will be coupled with the same person. If in a period your result is higher than that of the other, you will receive 135 points. The other gets 35 points. If your result is lower than that of the other, you will get 35 points. The other receives 135 points. In case of an equal result, you will both get 85 points.

After each period, you will be informed about the moves and results of the other for task A. The other gets to know your moves and results for task $\mathrm{A}$.

The highest value that you can reach at task A is 100. The highest value that can be reached at task B, is 50 .

Assume that at task A you reach a value of 70 (this is your result), and that the other reaches a value of 60 (this is the result of the other). You will earn 135 points on task A. The other earns 35 points.

Your total earnings in a period are the sum of your earnings at task A and at task B. Thus, your earnings are maximally 185 points in a period (maximally 135 points at task A plus 50 points at task B). The exchange rate is again 100 points equal 1 guilder.

The tasks that will be presented to you have exactly the same character as those in part 1, and they will also be presented in the same way. On your screen only the table giving the results is different.

On the handout that will now be distributed, a summary of the instructions is given.

To clarify matters 2 test periods will follow now. In these test periods you cannot earn money.

If you want to ask a question, please raise your hand.

If you want to study the instructions again, use the PageUp-button. If not, press $\mathrm{K}$.

As soon as everybody is ready, the 2 test periods will start.

[after the 2 test periods: as above]

[after 25 periods: as above.] 